\title{
PRÁXIS PEDAGÓGICA E CIBERFORMAÇÃO DOCENTE EM TEMPO DE COVID-19: PERSPECTIVAS E DESDOBRAMENTOS PEDAGÓGICO-CIENTÍFICOS
}

\author{
PEDAGOGICAL PRAXIS AND TEACHER CYBER INFORMATION IN COVID-19 \\ TIME: PERSPECTIVES AND PEDAGOGICAL-SCIENTIFIC DEVELOPMENTS
}

\author{
Úrsula Cunha Anecleto ${ }^{1}$ \\ Ediluzia Pastor da Silva ${ }^{2}$ \\ Luciana Oliveira Lago ${ }^{3}$
}

\begin{abstract}
Resumo
A realização de atividade remota na Educação Escolar, mediada pelas Tecnologias da Informação e Comunicação, nesse momento de pandemia causada pela Covid-19, despertam o interesse e a necessidade de discutirmos sobre movimentos ciberformativos como políticas públicas, que reverberem em práxis e desdobramentos pedagógico-científicos em sala de aula. Neste artigo, objetivamos refletir sobre a visão do professor da Educação Básica, da rede pública de ensino, em relação à utilização dessas tecnologias como artefatos mediadores da atividade pedagógica, tendo como cenário tanto o contexto anterior como durante a pandemia. Propõe-se como horizonte epistemológico a discussão sobre ciberformação docente, que supere o caráter técnico-instrumental desses meios tecnológicos. Metodologicamente, partimos de uma pesquisa qualitativa, de inspiração netnográfica, tendo como dispositivos para a construção de informações o questionário online, a partir do Google Forms, e a tertúlia digital, realizada pelo aplicativo de mensagem WhatsApp. Discutimos sobre a condição do professor para a realização dessas aulas online na rede pública, levando em consideração seu percurso formativo e a construção de atividades pedagógicas, a partir de perspectivas e de relações múltiplas entre docência e contexto social.
\end{abstract}

Palavras-chave: Práxis pedagógica; Ciberformação docente; Covid-19; TIC; Educação online.

\footnotetext{
Abstract

The performance of remote activities in School Education mediated by Information and Communication Technologies during the pandemic generates the need for reflecting upon cyber-informative movements as public policies that reverberate in pedagogical praxis and pedagogical-scientific developments at the classroom. In the article, we reflect upon the the teacher's perspective of Basic Education in public schools regarding the usage of technologies as mediator artefacts in pedagogical activity bearing in mind both the previous context and the pandemic situation. We introduce as our epistemological horizon the debate about cyber

1 Doutora em Educação pela Universidade Federal da Paraíba. Docente no Programa de Pósgraduação em Estudos Linguísticos e no Programa de Pós-graduação em Educação da Universidade Estadual de Feira de Santana.

E-mail: ursula.cunha@hotmail.com

ORCID: http://orcid.org/0000-0002-3027-9474

2 Mestra em Educação e Diversidade pela Universidade do Estado da Bahia. Docente na Rede Municipal de Educação de Queimadas e na Rede Municipal de Educação de Valente.

ORCID: http://orcid.org/0000-0001-9914-8408

${ }_{3}^{3}$ Mestra em Educação de Jovens e Adultos pela Universidade do Estado da Bahia. Docente na Rede Pitágoras.

ORCID: http://orcid.org/0000-0002-3027-9474
} 
information on teaching in a sense that overcomes the technical-instrumental nature of technological mediums. Regarding methodology, we depart from a qualitative research design that draws inspiration from netnography, collecting data both via an online Google Forms survey and from WhatsApp message interchanges. We discussed upon the teacher's adequacy to give online classes in public schools considering his or her training and pedagogical activity, from multiple perspectives and relationships between teaching and social context.

Keywords: Pedagogical praxis; Cyber information; Covid-19; Information and Communication Technologies; Online education.

\section{Introdução}

Desde a proliferação da Covid-19 - doença causada pelo novo coronavírus na maior parte dos estados do Brasil ${ }^{4}$, provavelmente em março de 2020, muitos setores da vida social, para não ficarem estagnados, estão enfrentando a difícil missão de reinventar seus modos/suas bases de funcionamento e/ou seu significado sociocultural e pedagógico-científico. Entre essas esferas que fazem parte da sociedade contemporânea, destacamos a Educação que, em um movimento de ubiquidade, tem seu sentido ampliado e relativizado o espaço escolar como único locus para a construção de conhecimento.

A partir das novas relações socioeducacionais proporcionadas pela pandemia, o espaçotempo 5 (ALVES, 2003) formativo foi ampliado e, com isso, novas metodologias de ensino e artefatos das Tecnologias da Informação e Comunicação (TIC) passaram a fazer parte, de forma mais intensa, da paisagem escolar. Embora compreendamos que as TIC já são utilizadas, principalmente as tecnologias móveis, por muitas pessoas diariamente em diferentes contextos sociais, no espaço escolar ainda representa um desafio a inclusão dessas tecnologias como meios que promovam a construção do conhecimento, de forma colaborativa, tanto pela escassez

\footnotetext{
${ }^{4}$ A Covid-19, doença provocada pelo novo Coronavírus, corresponde a uma pandemia que se alastrou de forma planetária, atingindo vários países do mundo, dentre eles o Brasil.

${ }^{5}$ Utilizamos essa forma de grafar espaçotempo tendo como referência os estudos de Nilda Alves (2003). Para a autora, a constituição dessa categoria tem como objetivo a superação da dicotomização herdada da ciência moderna, em relação a tempos e a espaços de aprendizagem, que ocorrem em momentos e locais previamente definidos, para uma ideia de ubiquidade. Assim, para apresentar a Educação online, tornou-se oportuno o resgate dessa concepção, ratificando o nosso posicionamento sobre a construção de conhecimento na cibercultura, por meio de espaços online.
} 
de políticas públicas em relação à formação de professores para a construção de estratégias pedagógicas em ambientes digitais, como pela limitada infraestrutura de muitas escolas públicas em relação a recursos tecnológicos, conexão banda larga de boa qualidade, dentre outros fatores.

Para além desses aspectos teórico-pedagógicos, torna-se urgente nesses espaços educativos "o estabelecimento de uma verdadeira cultura de compartilhamento, cooperação e trocas abertas, atributos indissociáveis do contexto das redes" (NUNES et al, 2014, p. 62). Nesse período de atividade remota, também na área de Educação, em que as TIC passaram a ser artefatos mediadores da prática pedagógico-científica, é preciso problematizar a formação do professor para que, de forma crítico-reflexiva, faça uma aposta enactante (HANNOUN, 1998) em outras metodologias de ensino, que correspondam à superação do dualismo homem e máquina, tendo como pressuposto a construção colaborativa de conhecimento.

À vista dessas considerações iniciais, objetivamos refletir sobre a visão do professor da Educação Básica, da rede pública de ensino, em relação à utilização das tecnologias da informação e comunicação como artefatos mediadores da atividade pedagógica, tendo como cenário tanto o contexto anterior como durante a pandemia, devido à Covid-19, quando práticas educativas presenciais foram reconfiguradas para o modelo de Educação Online. Nessa perspectiva, propõe-se como horizonte epistemológico a discussão sobre ciberformação docente, que supere o caráter apenas instrumental dessas tecnologias, regido essencialmente por meio de técnicas baseadas em conhecimentos empíricos (HABERMAS, 2014), mas que se fundamente em um processo teórico-científico oportunizado por autocompreensões do contexto socioeducacional dos docentes.

Metodologicamente, partimos de uma pesquisa qualitativa, de inspiração netnográfica, tendo como dispositivos para a construção de informações o questionário online, pelo Google Forms, e a tertúlia digital, realizada pelo aplicativo de mensagem WhatsApp, com docentes de escolas públicas de quatro municípios do mesmo território no interior do estado da Bahia. Pretendemos, com este estudo, estabelecer diálogos sobre a proposta de aulas online na rede pública em tempo de pandemia, levando em consideração que a ciberformação tem o potencial de promover mudanças significativas na práxis pedagógica docente.. 


\section{Ciberformação e práxis pedagógica: diálogos urgentes}

Diante do contexto pandêmico da Covid-19 e da determinação governamental, nos três níveis de governo (federal, estadual e municipal), de um status de isolamento e afastamento físico como forma de minorar os efeitos dessa pandemia, nos revelou a oportunidade de aprofundar a reflexão sobre o estilo de sociedade em que vivemos e, atrelado a isso, a organização dos serviços públicos oferecidos à comunidade, dentre esses serviços destacamos o direito à Educação escolar básica.

Fazemos parte do coletivo de professores e professoras pesquisadores e pesquisadoras que defendem e reforçam que se deve assegurar o direito social de acesso e permanência à Educação pública, e que tal direito não seja cerceado para os estudantes de diversos níveis de ensino no país e, por conseguinte, nos municípios locus desta pesquisa. Nesse sentido, estamos exercendo a nossa prática docente, pesquisando e acompanhando as decisões do poder público no que diz respeito aos decretos e documentos que regularizam a oferta da Educação básica no país em tempos de pandemia e como os docentes têm se posicionado e atuado neste contexto pandêmico.

Sobre essa questão, o Ministério de Educação (MEC) publicou no Diário Oficial da União (D.O.U), em 17 de março de 2020, a Portaria 343/2020, que "dispõe sobre a substituição das aulas presenciais por aulas em meios digitais enquanto durar a situação da pandemia do Novo Coronavírus - COVID-19" (D.O.U, online), sem, ao menos, instituir políticas públicas emergenciais que subsidiassem o trabalho do professor em ambientes virtuais e, de mesma forma, o nível de conectividade dos estudantes, principalmente aqueles que residem fora dos grandes centros urbanos.

Entendemos que práticas educativas atuais devem promover, no espaço escolar, a itinerância dos estudantes pelos mais diversos ambientes virtuais que fazem parte da cultura digital, ampliando, assim, possibilidades de participação social desses sujeitos em redes interacionais, com vistas à construção de conhecimento, de forma colaborativa. Sobre isso, concordamos com Shirky (2011) quando apresenta a escola como espaço propício para motivar os alunos para uma cultura constante de participação em diversas esferas comunicativas sociais, dentre elas destacamos os espaços digitais. 
Nesse sentido, a priori, a substituição de aulas presenciais por mediação pedagógica no formato de Educação Online, conforme apresentado na Portaria ministerial, poderia representar um ganho para a formação dos estudantes da Educação Básica, se não fossem as "tímidas políticas públicas educacionais e tecnológicas nas últimas décadas, dos parcos investimentos em acesso, logística e formação humana (gestores e professores)" (HETKOWSKI, 2020, p. 1).

Defendemos a implantação/cumprimento de políticas públicas permanentes que interliguem fatores humanos e infraestruturais para a Educação na sociedade em rede; dentre esses fatores, destacamos como objeto de discussão neste artigo a formação de professores para o exercício da prática pedagógica, por meio de uma práxis, através de um movimento teórico-científico e contextual (HABERMAS, 2014). O cenário atual, em que se visualiza a proliferação de uma doença de forma planetária, nos provoca a aprofundarmos ainda mais a reflexão sobre a interconexão mundial, fenômeno denominado pelo sociólogo Manuel Castells (2005) como sociedade em rede, com inventividade científica.

Nesse tipo de sociedade, vivenciamos um processo de mudança social que, além de outras imposições, nos coloca como seres capazes de adaptar-nos às mudanças culturais e às formas de tecnologias vigentes para, assim, potencializar outras/novas formas de produção de conhecimentos científicos, que gerem, também, implicações nos modos de ensinar e de aprender. Integrados a essa sociedade que por si só abarca uma geração que reconhece as TIC como potencializadoras de novos espaços agentivos, que possibilitem aos docentes atuarem no contexto social, refletimos sobre a necessidade de uma ciberformação docente que promova outra práxis educativa, no intuito de refletir com professores de que forma essas tecnologias podem ampliar/potencializar ações pedagógicas na sala de aula.

As TIC, desde a suspensão das aulas presenciais, tornaram-se os únicos meios para o ensino formal através das aulas online, e esse contexto pandêmico praticamente obrigou muitos docentes da Educação Básica a buscarem a imersão em ambientes tecnológicos sem, muitas vezes, refletirem sobre as potencialidades dessas redes. Portanto, a proposta de ciberformação como uma política pública deve ser promovida pelos governos federal, estadual e municipal, e o cenário atual revela a necessidade de uma ação permanente, que resulte em produções teórico- 
científicas sobre o fazer docente, fato esse evidenciado nesse momento em que 0 professor precisa exercer sua profissão online, por meio de suportes remotos.

Estamos presenciando, então, a necessidade de fortalecer o trânsito desses sujeitos por processos formativos que ampliem a sua percepção quanto às contribuições dos meios tecnológicos na prática pedagógica. Ressaltamos que, durante a atividade profissional do professor, serão necessárias mudanças em relação a metodologias de ensino, à concepção educacional, a artefatos mediadores da prática pedagógicas, independente de contextos excepcionais, como o que vivenciamos na atualidade. Isso porque a própria sociedade em rede, de base tecnológica, apresenta, em seu design conceitual, outros papéis docentes, que não apenas aquele que se limita à transmissão de informações que podem ser recuperadas pelos alunos através de um click na Internet.

Essa mudança de status quo nos demonstra "[...] certa tensão que ainda existe em relação à descentralização do papel do professor e a modificação de metodologias de ensino, a partir do advento das tecnologias" (ANECLETO, 2018, p. 296). Dessa forma, a ciberformação docente pode convergir para um movimento de redefinição da profissão, alicerçada nas experiências profissionais e em um contínuo incentivo à produção de conhecimento, ao desenvolvimento de habilidades e atitudes que estimulem perspectivas crítico-reflexivas para a construção de pensamentos autônomos (NÓVOA, 2002).

Por isso, falar em ciberformação, principalmente na conjuntura de trabalho remoto vivenciada pelos docentes da rede pública de ensino no país, demanda uma constante mobilização dos sujeitos envolvidos para que o sentimento de construção coletiva permeie todo o processo formativo, percebendo que o conhecimento se constrói à medida em que as relações e os diálogos se ampliam. Ao abordarmos sobre a ciberformação tendo como interface a práxis pedagógica, oportunizamos um espaçotempo reflexivo gerado no âmbito da própria realidade educacional que muitos docentes têm vivenciado, também, durante o processo de atividade remota.

A ciberformação, então,

[...] se configura em espaços formativos, em que os sujeitos se permitem dialogar sobre os diversos aspectos do contexto pedagógico; os pressupostos teóricos que fundamentam essa formação; os dispositivos 
metodológicos que auxiliam na aplicação de diferentes atividades (SILVA; ANECLETO, 2019, p. 226).

Ademais, defendemos tais concepções que aliam TIC/ciberformação para que o exercício da práxis pedagógica garanta maior oportunidade de construção de experiências emancipatórias pelos docentes que fazem parte da rede pública de ensino. Prova-se no atual contexto social que entrou para a História da humanidade que, aquilo que antes chegou a ser proibido em muitas salas de aula, como o uso do celular e a resistência de muitos docentes para incluir o uso das TIC em sua metodologia de ensino, passou a ser a alternativa viável para a prática pedagógica em tempos de pandemia, tornando cada vez mais evidente e urgente uma ciberformação para a o exercício da prática docente.

\section{Pandemia e ensino público: entre o antes e o agora na Educação Básica}

Entre os 50 escolares que participaram da pesquisa, identificou-se predominância do sexo feminino $(62,0 \%)$ e de crianças na faixa etária dos cinco anos, $60 \%$. Embora a localidade da escola seja em um bairro considerado não periférico, as crianças que ali estudam pertencem a comunidades periféricas.

No exercício em busca de construções urgentes, utilizamos o próprio ciberespaço para estabelecermos diálogo com os participantes da pesquisa. Para tal, partimos da abordagem de pesquisa qualitativa, de cunho descritivo-analítico, inspirado-nos no método netnográfico. Através da netnografia, bem como a utilização do procedimento de uma revisão/atualização de alguns aportes teóricos sobre a temática em estudo, por meio dos diálogos contínuos estabelecidos antes e durante essa pandemia, obtivemos, para a geração das informações aqui apresentadas, a participação inicial de 29 docentes da rede pública de ensino, tanto da esfera municipal como estadual, de quatro municípios do interior da Bahia.

Optamos pela inspiração netnográfica por esse método possibilitar a comunicação entre os sujeitos da pesquisa (pesquisadores e colaboradores) mediada pelas TIC, ação iniciada antes do momento pandêmico, a partir da realização de um 
projeto de pesquisa ${ }^{6}$, iniciado em 2018, com docentes da Educação Básica da região. Nesse sentido, como afirma Kozinets (2014, p. 62), a netnografia oportuniza ao pesquisador "[..] reconhecer a importância das comunicações mediadas por computador nas vidas dos membros da cultura [...]", a partir do movimento de itinerância e de trânsito que esses docentes já possuíam nos espaços digitais.

Por se tratar de um método interpretativo que considera tanto o envolvimento de pesquisadores como dos sujeitos participantes, neste artigo professores da Educação Básica que atuam na rede pública da esfera municipal e da estadual nos municípios locus, a perspectiva netnográfica contribuiu de forma relevante para o processo de construção de informações na pesquisa devido aos pesquisadores apresentarem familiaridade com os participantes da pesquisa, que já atuavam em comunidades físicas e em espaços digitais comuns, antes do processo investigativo.

Nesse sentido, foram observadas algumas etapas netnográficas: escolha do corpus de pesquisa (posicionamentos textuais dos docentes sobre a utilização das TIC em sala de aula e a perspectiva de atividades remotas durante a pandemia); definição dos sujeitos participantes da ação dialógica a partir dos dispositivos investigativos (docentes da esfera pública da Educação Básica de quatro municípios da mesma região do interior da Bahia que, de forma voluntária, participaram de todas as etapas de pesquisa anteriores a este recorte); definição do enfoque e dos ambientes online para a interação entre os participantes (questionário a partir do Google Forms e aplicativo WhatsApp para a tertúlia digital); interpretação interativa das informações construídas nesses espaços virtuais.

O dispositivo para construção de informações questionário online contou com seis questões abertas e 13 fechadas, que versavam sobre a experiência profissional docente, utilização das TIC pelo aluno no espaço escolar e no contexto da sala de aula; organização de prática pedagógica com o uso dessas tecnologias; concepções teórico-metodológicas sobre ambientes digitais, dentre outras questões que começaram a ser analisadas antes do processo de trabalho remoto e tiveram a discussão continuada durante esse momento pandêmico.

\footnotetext{
${ }^{6} \mathrm{O}$ Projeto de pesquisa que subsidiou este artigo, como um recorte das informações construídas no processo, foi submetido ao Conselho de Ética em Pesquisa (CEP) e aprovado pelo parecer consubstanciado CAAE: 19156619.2.0000.0057.
} 
Dos professores respondentes ao questionário, 58,6\% atuam em escolas do espaço urbano, que contam com acesso à Internet banda larga e alguma, mesmo que limitada, infraestrutura técnica e equipamentos tecnológicos, a exemplo de notebooks e datashow; $41,4 \%$ lecionam em unidades situadas no espaço rural, escolas, muitas vezes, que possuem acesso limitado à rede de Internet, fato que já dificultava o trabalho com as TIC nos momentos presenciais antes da Covid-19 e que, por isso, não oportunizou a implementação da atividade remota durante a pandemia.

Ao perguntarmos como ocorria o trabalho com as TIC na sala de aula antes da Covid-19, muitos docentes apresentaram que já utilizavam essas tecnologias como recurso pedagógico, principalmente como meio para a realização de pesquisas, principalmente extra sala de aula, tanto pelo docente como pelo aluno; aulas expositivas com a utilização de slides e retroprojeção com data show. Percebemos que muitas dessas atividades centram-se mais no uso técnico das TIC do que em seu potencial interativo-comunicativo, tais como apresentam alguns docentes: "Sou leiga quanto ao uso das tecnologias, vez por outra utilizo o data show para trabalhar slides e/ou algum vídeo ou filme" (DOCENTE \#B); "Ainda estou tentando me adaptar as essas inovações tecnológicas, por isso uso muito pouco" (DOCENTE \#T); "Faço uso com aulas com lâminas de slides, uso portal de infocentro na escola, usamos o aparelho celular como fonte de busca, pesquisa" (DOCENTE \#X).

Entendemos, no entanto, que a atividade docente, quando mediada por essas tecnologias, exige do professor um empenho que vai além do conhecimento teórico sobre esses meios e/ou habilidades técnicas e instrumentais. Segundo Lévy (1999), para o ensino com/pelas tecnologias, é necessária a participação ativa do professor na cultura digital, de forma a perceber as múltiplas possibilidades que são oferecidas aos alunos diante do inesgotável oceano de informações do ciberespaço.

Docentes, a exemplo de \#T, afirmam pouco utilizar esses artefatos na prática pedagógica por não se sentirem preparados tanto em relação à própria ação instrumental das TIC (utilizar, por exemplo, programas de computadores ou softwares para a produção de textos etc., como também realizar download e uploads de arquivos) quanto aos objetivos de ensino e de aprendizagem que elas podem proporcionar, a partir de seu componente de atuação. No entanto, apesar de esses fatores quanto à operacionalização da técnica serem limitantes a essa ação, 
muitos professores relataram que a falta de infraestrutura tecnológica das escolas onde atuam é o maior fator que dificulta a interação de professores e alunos com as TIC, como apresentado nos relatos a seguir: "Apesar de não ter muitos meios para realizar trabalhos em sala de aula, utilizo data show em aulas e pesquisas utilizando celulares dos alunos" (DOCENTE \#D); "Diante da dificuldade de internet realizo apenas pesquisa (DOCENTE \#R).

Observamos através dos registros realizados pelos professores no questionário online que a prática pedagógica ainda se mantém com pouca modificação frente à utilização das TIC, já que a exposição de conteúdo ainda é a forma didática mais comum nas aulas, seja através de vídeos ou slides. Entretanto, a partir do posicionamento dos docentes, inferimos a preocupação quanto à necessidade de formação e de políticas públicas governamentais, seja com relação à ampliação de um capital teórico-científico sobre essas tecnologias, que reverbere em novas/outras inventividades pedagógicas, seja pela aquisição de equipamentos que os auxiliem na ação de ensino.

Apresentamos que as atividades propostas aos alunos por esses docentes, a exemplo de pesquisar vocabulário, assistir a vídeos ou ouvir música etc., quando e se oportunizadas a partir da interação do discente com/pelas TIC, de forma críticoreflexiva, proporcionará a esses sujeitos a participação ativa na sociedade em rede. Esperamos, portanto, que através de diálogos ciberformativos o docente possa buscar caminhos que valorizem suas vivências e experiências, num movimento de produção coletiva de saberes teórico-práticos e científicos próprios à profissão, para o estabelecimento de espaços convergentes de conhecimento.

Dialogar sobre essas questões com esses docentes, também nesse momento em que a Educação Online se tornou uma marca do sistema educativo nacional, só reforça nosso entendimento quanto à importância de processos formativos para a construção de outras possibilidades de práticas de ensino e de aprendizagem, que contribuam com um movimento de práxis pedagógica. Essa concepção implica o reconhecimento das TIC como interfaces didáticas, que visam à formação do aluno interactante, que age sobre o objeto de aprendizagem.

Outro momento para a construção de informações oportunizado pelos diálogos mediados pelas TIC com os docentes participantes deste estudo ocorreu 
durante o auge da proliferação da Covid-19 no Brasil e o necessário afastamento físico como medida de biossegurança. Para que continuássemos com a interação, utilizamos também como dispositivo a tertúlia digital ${ }^{7}$, a partir do aplicativo de mensagens WhatsApp, para que fossem promovidas reflexões sobre a possibilidade de aulas online para a educação básica do município.

Para a realização da etapa da tertúlia digital, contamos com a participação de seis docentes, cujos critérios de seleção dos sujeitos foram: atuação em escola que, no momento da construção de informações para este artigo, discutiam sobre a possível implantação da atividade remota (ou escolas que já estavam em processo de adaptação dessa proposta emergencial de educação); fazerem parte das propostas iniciais de pesquisa do projeto guarda-chuva; professores dispostos a participarem do estudo por considerarem a discussão pertinente e relevante ao seu contexto socioeducacional no momento da pandemia.

Para promover a interação, foram apresentadas as seguintes questões: 1) Você utilizava as Tecnologias da Informação e Comunicação nas suas aulas antes da pandemia da Covid-19? 2) No contexto atual, quando as aulas online estão sendo aderidas e exigidas como única alternativa para o ensino formal, como tem sido a sua experiência docente?

A docente da rede estadual de uma cidade do interior da Bahia da região locus, \#N, que integra o quadro de efetivos de uma escola situada no espaço rural, apresentou a seguinte contribuição sobre as temáticas propostas:

1. Esporadicamente. Acredito que por ter um pouco de dificuldade ao manusear de forma adequada os instrumentos necessários, não procurei aprender. Até porque é muito mais cômodo ficar na zona de conforto. Então, preferi continuar as aulas com as mesmas práticas pedagógicas.

2. Eu estou tentando me adaptar. Apesar das dificuldades o aprendizado vai ocorrendo gradativamente, mas a experiência está sendo muito interessante e positiva. (DOCENTE \#N)

\footnotetext{
${ }^{7}$ A palavra tertúlia tem origem espanhola e, embora não seja muito conhecida, refere-se, segundo o dicionário Priberam da Língua Portuguesa, a uma reunião familiar, a uma assembleia literária ou até mesmo a um agrupamento de amigos. Trata-se de um grupo de pessoas reunidas para dialogar sobre algum assunto previamente determinado. Disponível em: https://www.priberam.pt/DLPO/Tert\%C3\%BAlia. Acesso em: 14 de dez. de 2019.
} 
Apesar de vivermos, na atualidade, a cultura da interatividade (SILVA, 2012), oportunizada por uma superação da pedagogia da distribuição de informação, é fato que existem docentes que ainda encontram dificuldades em atrelar possibilidades educativas às TIC, conforme mencionado pela docente \#N. Entretanto, mesmo a professora reconhecendo possuir dificuldade no processo de ressignificação didática de conteúdos que seriam ministrados no espaço presencial para o online, compreende ser necessário se adaptar à Educação Online no período da atividade remota, aderido pela escola onde atua, a partir da disponibilização de materiais didático-pedagógicos e da organização de espaços de aprendizagem como um devir humano.

Como interfaces digitais para a prática pedagógica, \#N tem utilizado durante a atividade remota as plataformas interativo-comunicacionais Google Meet, TEAMS, emails, Google classroom, além da rede social Facebook e plataformas pedagógicas disponibilizadas pelo Instituto Anísio Teixeira, superando as barreiras/empecilhos que surgem ao longo da sua prática pedagógica. A docente \#AV, pertencente a uma escola da esfera estadual de um dos municípios locus, situada na área urbana, nos apresenta as seguintes respostas/provocações:

1.Não.

2. Algumas atividades são enviadas para os alunos pelo whatsapp ou pelo google clasroom. Também são sugeridos alguns vídeos para assistir no youtube. É um faz de conta. Sinceramente, acho que poucos alunos estão aprendendo alguma coisa. Nós, professores, não estamos preparados para essa modalidade de ensino e nossos alunos que sempre querem fazer algo se for para nota também não. Os alunos não demonstram interesse quando percebem que a atividade proposta não vale nota. (DOCENTE \#AV)

Ao apresentar de forma bem lacunar sobre a utilização das TIC na prática pedagógica apenas com um "não", a docente nos leva a intuir que, muitas vezes, devido ao excesso de cobrança por certas metodologias ou práticas de ensino sem, contudo, oferecer recursos técnicos, a exemplo de infraestrutura em relação à banda larga ou equipamentos suficientes para a realização de aulas por esses meios, além de processos formativos pedagógicos necessários, gera no professor um sentimento de insatisfação, pois é pressionado a realizar práticas para as quais ainda não está seguro.

Quanto à atuação da professora pela Educação Online neste momento de trabalho remoto, apesar de apresentar algumas atividades realizadas na 
escola, problematiza se, realmente, essas ações estão gerando aprendizagens significativas. Isso porque, ao ver de \#AV, a falta de preparação dos docentes da escola para o uso das TIC como meio pedagógico e a cultura escolar estabelecida por muitos alunos em relação à validação de atividades a partir de recompensas imediatas, a exemplo de "ganhar" ponto por exercícios realizados, são fatores que afetam a eficácia do trabalho online.

A docente \#C, lotada em uma escola estadual, situada no espaço urbano, por ocupar o cargo de vice-diretora da instituição, apresenta uma dupla visão sobre a temática, tanto enquanto gestora quanto como docente em exercício de sala de aula. Sobre as questões problematizadoras, refletiu:

1- Sim. Com limitações. Aqui, na escola, fazemos uso de datashow acoplado ao computador para apresentar vídeos, slides, fotos e áudios. Há um curso feito pelos professores (UPTE) que instrui como usar alguns recursos do Google Sala de Aula, Formulários Google etc., mas poucos professores tiveram acesso ao curso (só professores concursados) e pouquíssimos professores usavam estes recursos para dar aulas.

2- Como vice-diretora, tenho acompanhado um pouco do trabalho dos professores que precisam dar aulas nesta condição, bem como de alguns alunos. É uma situação desafiadora porque está exigindo que professores que não foram devidamente preparados tenham que trabalhar com recursos que não conheciam ou que conheciam pouco, alterando a metodologia de suas aulas. Um dos maiores entraves é o fato de que muitos alunos da escola onde trabalho serem de zona rural, locais de difícil acesso e sem internet, de modo que nem todos os alunos da escola conseguem acompanhar as aulas. Há alunos, inclusive, que não conseguem acompanhar as aulas no Google Sala de Aula e os professores decidiram ministrar as aulas por WhatsApp por causa disso.

A docente/gestora, ao apresentar uma resumida caracterização das implicações que as atividades online reverberaram na instituição escolar da qual faz parte, nos convida a ratificar a importância de políticas públicas educacionais que, realmente, tenham como horizonte os contextos relacionais dos sujeitos por elas atendidas. Nesse sentido, promover uma formação aos docentes das escolas estaduais na Bahia, a exemplo do Uso Pedagógico de Tecnologias Educacionais (UPTE), como mencionado pela docente, constituir-se-ia como fator importante para os professores se contemplasse reais necessidades de conhecimento desses sujeitos, identificadas a partir de uma escuta sensível a esses profissionais.

Ademais, a docente \#C descreve a situação de acesso às TIC e à infraestrutura técnico-tecnológica que vivenciam muitos alunos de escolas públicas em 
nosso país, quando apresenta como grande entrave para a realização de atividades didáticas, durante o período de atividade remota, a falta de acessibilidade a esses meios. Bonilla e Oliveira (2011, p. 25) contribuem com a problematização do que denominamos de percurso de exclusão a aspectos técnico-tecnológico-estruturais, ao apresentarem que, muitas vezes, "[...] programas e ações propostos de forma isolada, desarticulados das demais políticas públicas, e que não levam em consideração a complexidade dos processos vividos pelas comunidades" não ratificam as TIC como meios para integração pedagógica por uma perspectiva social transformadora.

Assim, entendemos que se torna necessário, nos espaços escolares, não apenas durante o período de Educação Online necessário devido ao momento de pandemia, fornecer condições materiais para que alunos, docentes, gestores, e outros integrantes desse espaço social, tenham possibilidades de participar, produzir, transformar o conhecimento em qualquer instância sócio-comunicativa, dentre elas as que pertencem à esfera digital.

A docente \#M, pertencente à rede pública municipal, descreve um quadro em sua escola sobre as TIC na sala aula, antes e depois da atividade remota:

1 - Não. Leciono numa escola em área rural do município de Araci, na qual há apenas um data-show e 01 notebook, além de uma caixa de som disponíveis para toda a escola - que conta com turmas da creche até o nono ano. As barreiras técnicas influenciam e muito no não uso: falta de funcionário para o manuseio dos recursos, chegada muito atrasada na escola, poucos recursos disponíveis e a minha pouca habilidade sobre os recursos.

2 - Não houve uma imposição acerca da manutenção das aulas por meio de recursos digitais. Trata-se de uma proposta reconhecida para aquelas instituições que assegurassem a qualidade das atividades. Essa possibilidade é inaplicável onde ensino, dificuldade reconhecida pela secretaria de educação do município, haja vista a realidade dos estudantes, submetidos a restrições inúmeras, como alimentar, logo, não dispõem de recursos mínimos para esse "novo formato". Haverá reposição das aulas. Essa foi a determinação da gestão.

A docente confirma, assim como apresentado nas tertúlias descritas, anteriormente à pandemia, sobre as condições precárias em relação à infraestrutura tecnológica que enfrentam muitas escolas, tanto da rede estadual quanto municipal, em nosso estado. Também, informa que, ao optar pela não realização de atividade remota durante esse período de isolamento físico, a secretaria de Educação do município onde leciona problematizou reais condições dos docentes e dos discentes 
para a realiação da Educação online, encontrando como alternativa a reposição de aulas, em um tempo futuro oportuno.

Ao dialogarmos com as informações construídas tanto pelo Google Forms como pela tertúlia digital, visualizamos situações que reforçam a importância de setores públicos agenciar ciberformações docentes para o entendimento das TIC como meios interativos, que promovam a construção de conhecimento. Além disso, docentes apontam a precariedade dos investimentos públicos em recursos técnicos e infraestruturais nas instituições escolares, o que reverberam no fazer teórico-científico docente e na proposição de um movimento de práxis educativa que atenda a especificidades da era atual sem, contudo, desvincular o local do global.

À vista dessas discussões, defendemos, a partir de processos ciberformativos, a construção de uma concepção emancipatória na realização de atividades online, que permita a docentes e a discentes superarem apenas a promoção de tarefas escolares disponibilizadas em ambientes digitais, como uma ação eminentemente escolarizada. Mas como uma atitude que possibilite que esses sujeitos produzam conteúdos digitais articulados às necessidades educativas de seus alunos, contribuindo, assim, para a formação de sujeitos autores e ativos e não apenas consumidores dos produtos/conteúdos dessas interfaces.

Por essa concepção, a docente \#J, também pertencente à rede estadual de ensino, ao interagir com as questões propostas na tertúlia analisa que:

1. As tecnologias digitais são ferramentas capazes de auxiliar o docente a criar um ambiente de aprendizagem mais dinâmico, participativo e atrativo. Sendo assim, sempre busquei utilizá-las em sala de aula, mesmo antes da pandemia, fazendo uso de vídeos, atividades on-line, Feedback de atividades através de redes digitais como WhatsApp, e-mail, uso de jogos em sala, e de plataformas digitais como Google Eath e infográficos acessados através de sites, atividades com uso de Chromebook, enfim. São algumas das atividades que desenvolvia de forma remota.

2. O cenário atual escancarou ainda mais a desigualdade que marca nosso país, a diferença de acesso à tecnologia fez com que estudantes e docentes da rede privada de ensino conseguissem manter, mesmo que de forma pouco convencional, a rotina de aulas, atividades e provas, enquanto os estudantes da escola pública não têm essa possibilidade. Como atuo nas duas redes (privada e público) visualizo com muita clareza essa impossibilidade e distorção, que se reforça principalmente entre alunos que vivem na zona rural, onde a precariedade de acesso a tecnologias como internet e sinal de celular (coisa simples) ainda é maior!

Tudo isso nos reforça a necessidade de busca por isonomia, e isso perpassa pela redução das desigualdades sem dúvida. 
Apesar de já possuir familiaridade com as TIC e compreender o potencial pedagógico desses artefatos e de suas interfaces, a docente destaca a desigualdade de acesso ao aparelho maquínico e a seu potencial pedagógico-interativo que ocorre, também, nas escolas. Ou seja: escolas públicas, tanto da esfera municipal como estadual nos municípios locus deste estudo, como ratificado pelos docentes participantes da pesquisa, não oferecerem acesso a computadores, notebooks, tablets etc., à rede banda larga, a softwares, entre outros produtos da era digital. Dessa forma, conforme apresentam esses docentes, os alunos que não têm acesso a esses meios em sua comunidade e/ou em sua casa ficam alijados de construir uma autonomia teórico-científica na sociedade em rede.

Portanto, afirmamos ser um dos papéis da escola e, por conseguinte, do professor, promover condições de acesso às TIC, a partir de uma cultura da participação e da autonomia, mobilizando situações para construção de conhecimento e de aprendizagens mais significativas. Como afirmam Bonilla e Oliveira (2011), a escola tem como uma de suas funções promover o imbricamento entre a vida, a comunidade, o ambiente de trabalho e a cultura local e global, motivados por ações teórico-científicas construídas não apenas devido aos processos emergenciais na Educação neste momento pandêmico; mas que reverbere, enquanto políticas públicas permanentes, em novas/outras aprendizagens para a atuação docente

\section{Considerações finais}

A sociedade em rede nos convida a refletir sobre uma esfera pública regida pela transformação e pelo compartilhamento de conhecimentos mediados pelas TIC, o que impulsiona mudanças que perpassam por todos os campos da vida humana, desde a ideia de consumo, sociedade e/ou formas de ver e vivenciar o presente e de projetar o futuro. Lidamos com uma evolução dinâmica, que altera a todo instante a relação do homem com o outro e consigo mesmo, ressignificando sua trajetória e sua forma de lidar com o conhecimento, também nos espaços escolares.

Nesse contexto social, valoriza-se o movimentar-se constante por processos ciberformativos, que levem em conta as especificidades dos sujeitos e suas necessidades de aprendizagem, antes, durante e, provavelmente, pós- 
pandemia da Covid-19, com a consolidação de propostas de atividades online que façam sentido aos docentes e, ao mesmo tempo, estejam ao alcance dos sujeitos aprendentes, tanto em relação à questão de infraestrutura tecnológica e à lógica de aprendizagem em rede.

A partir dessa perspectiva, apresentamos a ciberformação, que se configura por espaçotempos formativos, em que os sujeitos se permitem dialogar sobre os diversos aspectos do contexto pedagógico e dispositivos teórico-científicos que auxiliam no desenvolvimento de ações metodológicas com as TIC, tanto para a atuação nas atividades remotas como no período pós-pandêmico.

Entendemos, ainda, que, devido ao pouco acesso às tecnologias via interfaces pedagógicas nos ambientes escolares, muitos entraves, desconfianças e, às vezes, insegurança quanto à utilização desses artefatos são comuns no contexto escolar, tanto por parte dos docentes, como por outros atores da cultura escolar. Esse movimento de desconfiança nos leva a refletir sobre o desconforto experienciado por muitos professores quanto à proposta de trabalho remoto mediado pelas TIC, principalmente nessa conjuntura em que práticas didáticas são desenvolvidas em ambientes digitais como única alternativa para a realização de atividades escolares.

Por fim, processos ciberformativos como política pública governamental devem favorecer uma práxis pedagógica inventiva e atenta ao espírito desse novo tempo cibercultural, demandando, portanto, ações conjuntas que partam do Estado, dos atores educacionais e de instituições educativas que, tendo em vista a necessidade e o direito social à Educação que cada brasileiro possui e deve ser atendido, despertamse para a emergência de pensar sobre as TIC como meios para a construção de conhecimentos, de forma colaborativa

\section{REFERÊNCIAS}

ALVES, Nilda. Cultura e cotidiano escolar. Revista Brasileira de Educação, v. 23, Rio de Janeiro: maio/ago. 2003. Disponível em: https://www.scielo.br/scielo.php?pid=S1413-247820 03000200005\&script=sci arttext. Acessado em: 03 jun. 2020.

ANECLETO, Úrsula C. Formação de professores e ação educativa na era da cultura digital: algumas reflexões. Revista de Estudos e Pesquisas sobre Ensino 
Tecnológico (EDUCITEC), v. 4, n. 08, 14 nov. 2018. Disponível em: https://sistemascmc.ifam.edu.br/ educitec/index.php/edu citec/article/view/477. Acessado em: 03 jun. 2020.

BONILLA, Maria Helena Silveira; OLIVEIRA, Paulo Cezar Sousa. Inclusão digital: ambiguidade em curso. In: BONILLA, Maria Helena Silveira; PRETTO, Nelson De Luca (org.). Inclusão digital: polêmica contemporânea. Salvador (BA): Edufba, 2011.

CASTELLS, Manuel; CARDOSO, Gustavo (org.). A sociedade em rede: do conhecimento à acção política. Versão digital, 2005. Disponível em: https://egov.ufsc.br/portal/conteudo/ sociedade-em-rede-do-conhecimento-\%C3\%A0ac\%C3\%A7\%C3\%A3o-pol\%C3\%ADtica. Acessado em: 01 de dez.2019.

HABERMAS, Jürgen. Técnica e ciência como “ideologia”. São Paulo: Editora Unesp, 2014.

HANNOUN, Hubert. Educação: certezas e apostas. São Paulo: UNESP, 1998.

HETKOWSKI, Tânia Maria. Cibercultura e tecnologias: "substituição das aulas presenciais por aulas em meios digitais enquanto durar a situação de pandemia do COVID-19". Revista Endipe, 2020.

KOZINETS, Robert. Netnografia: realizando pesquisa etnográfica online. Tradução Daniel Bueno. Porto Alegre: Penso, 2014.

LÉVY, Pierre. Cibercultura. São Paulo: Editora 34, 1999.

NÓVOA, Antonio. Formação de professores e trabalho pedagógico. Lisboa: Educa, 2002.

NUNES, João Batista Carvalho et al. Cultura Digital: retrato do uso das tecnologias no estado do Ceará. Fortaleza: EdUECE, 2014.

SHIRKY, Clay. A cultura da participação: criatividade e generosidade no mundo conectado. Rio de Janeiro: Zahar, 2011.

SILVA, Ediluzia Pastor da; ANECLETO, Úrsula Cunha. Ciberformação Docente e Ambiente Virtual de Aprendizagem como Espaço de Práxis Educativa. In: PORTO, Cristiane Magalhães; OLIVEIRA, Kaio Eduardo de Jesus; CHAGAS, Alexandre Meneses. Educiber: dilemas e práticas contemporâneas. Vol. 2. 2 ed. Aracaju: Edunit, 2019. Disponível em: https://editoratiradentes.com.br/ebook/educiber2.pdf. Acessado em: 28 abr. 2020.

SILVA, Marco. Sala de aula interativa: educação, comunicação, mídia clássica, internet, tecnologias digitais, arte, mercado, sociedade, cidadania. 6 ed. São Paulo: Edições Loyola, 2012. 
Manuscrito recebido em: 15 de dezembro de 2020

Aprovado em: 30 de dezembro de 2020

Publicado em: 30 de dezembro de 2020 